\title{
Tumor of the caecum as a rare form of endometriosis - case report
}

Katarzyna Mech ${ }^{1}$, Tomasz Guzel ${ }^{1}$, Emilia Skowrońska ${ }^{1}$, Paweł Nyckowski ${ }^{1}$, and Maciej

Słodkowski ${ }^{1}$

${ }^{1}$ Medical University of Warsaw First Faculty of Medicine

April 28, 2020

\section{Hosted file}

20-0585 Article minus patient name.doc available at https://authorea.com/users/310096/articles/

440906-tumor-of-the-caecum-as-a-rare-form-of-endometriosis-case-report 


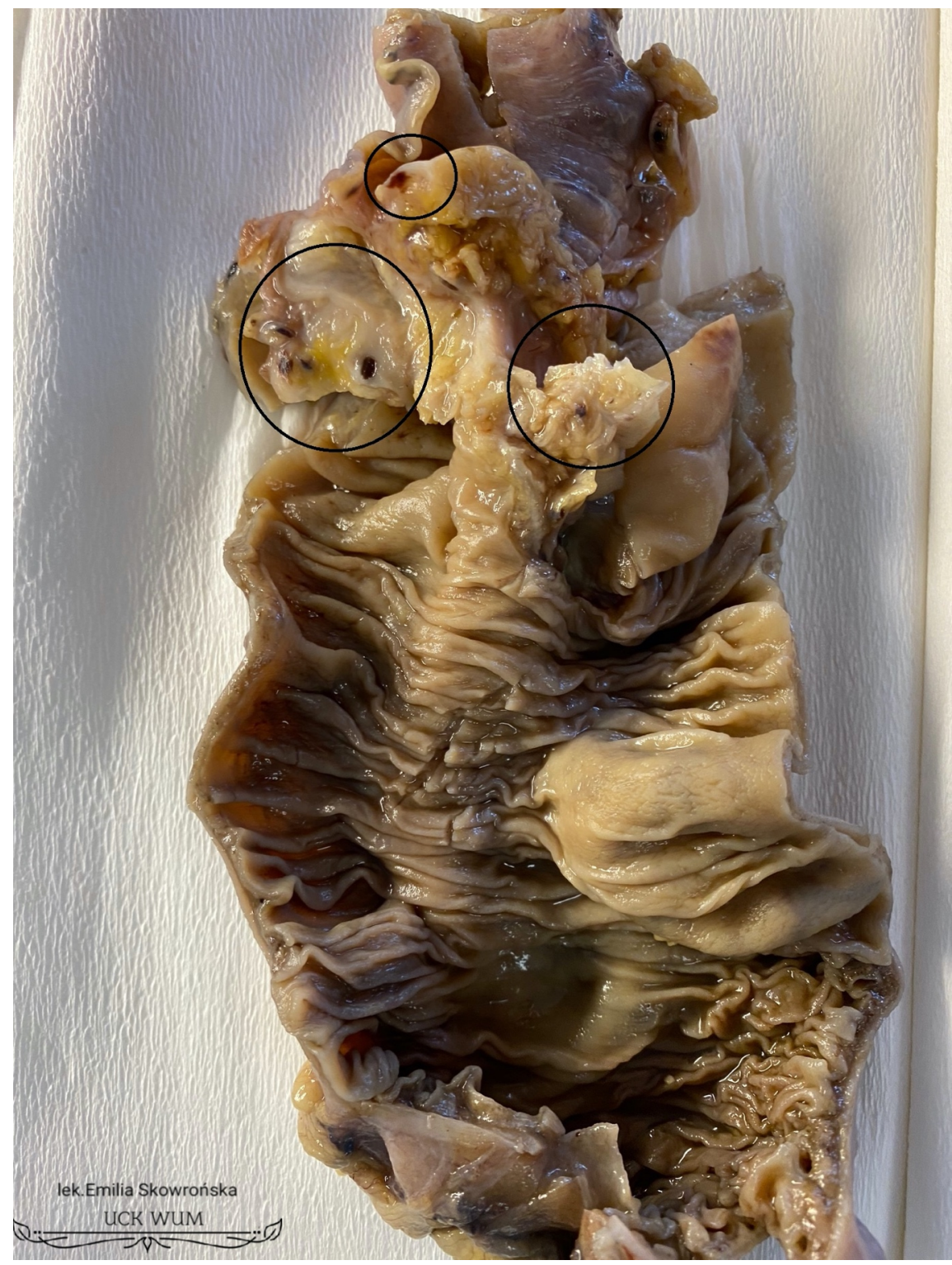



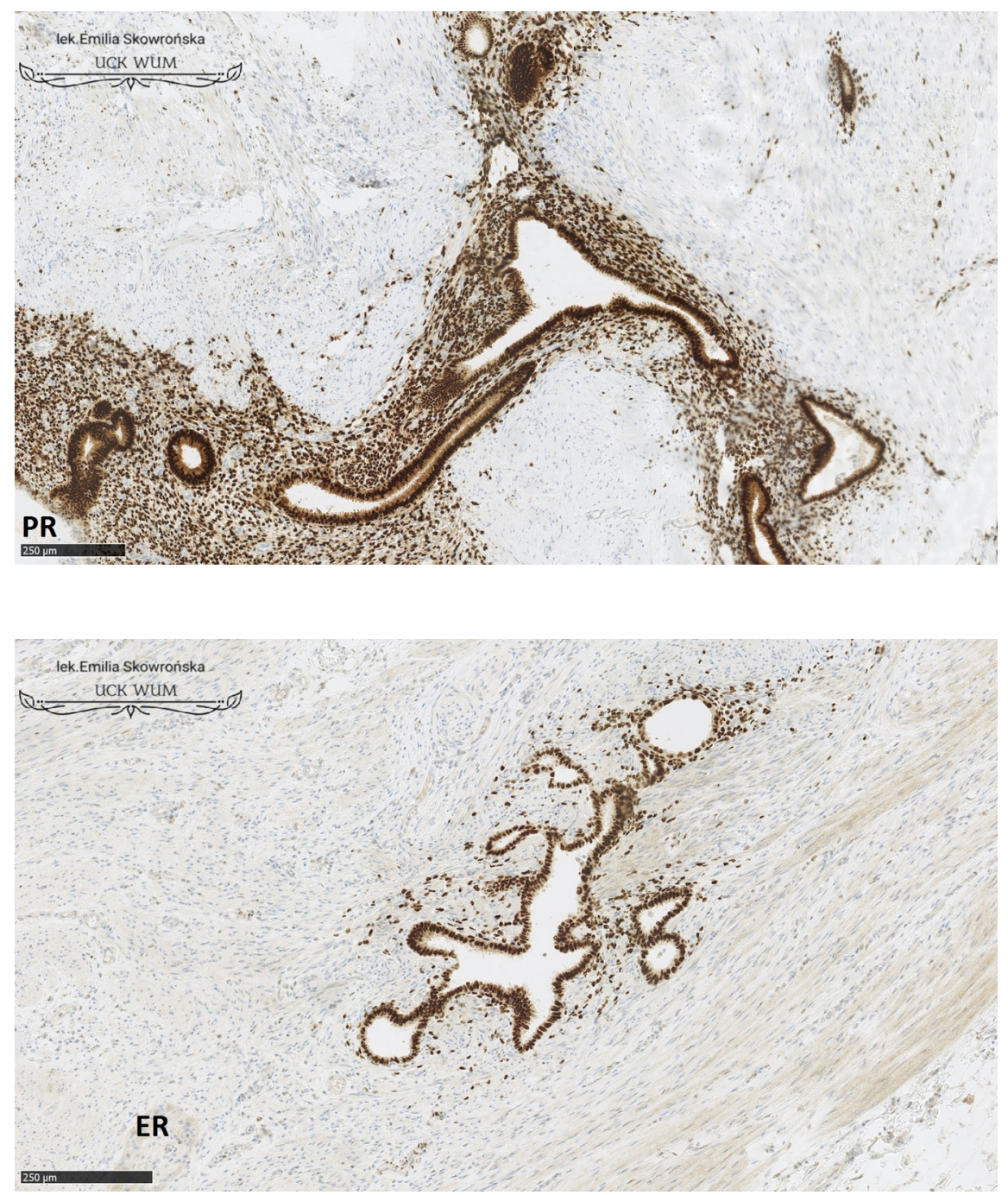